\title{
SPRAY APPLICATIONS TO TOMATO PLANTS IN GREENHOUSES. PART 1: EFFECT OF WALKING DIRECTION
}

\author{
Emanuele Cerruto, Giuseppe Emma, Giuseppe Manetto
}

\section{Introduction}

Protected crops in Sicily extend over an area of about 8800 ha with a production of $430660 \mathrm{t}$, mainly located in the South-East area, where the province of Ragusa totalises 4750 ha and 272 650 t [ISTAT 2008]. Greenhouses, however, due to confined spaces, high temperatures and high relative humidity, are very specific agro-ecosystems in comparison with the open field. To ensure high production, massive energy and chemical (fertilisers and pesticides) inputs are necessary.

A recent survey in Italy on about 200 farms [Cerruto 2008] showed that 40 percent of farmers make between 10 and 20 pesticide applications per year, and 28 percent more than 20 applications. The most frequent $(57 \%)$ volume rates are within the range 1000-2000 L/ha and the most common spraying machinery $(71 \%)$ are spray lances and spray guns.

These significantly high volume application rates and significantly high frequencies of application, put operators and the environment at high risk of exposure. In connection with the first consideration, it is known that operators, due to the usually uncomfortable climatic conditions, are reluctant to wear proper protective equipment (PPE), so the risk of pesticide absorption may be increased. Moreover, exposure may occur not only during spraying, but also during other activities, such as harvesting, if re-entry times are not adhered to.

Several Authors [Bjugstad 1996; Garrido Frenich 2002; Nuyttens 2005; Tuomainen 2002] report that a number of factors may influence exposure in field:

\section{Paper received 04.02.2009; accepted 11.05.2009}

Emanuele Cerruto, Associate Professor (ecerruto@unict.it), GiUSEPPE EMMA, Phd (gemma@unict.it), GIUSEPPE MANETTO, Researcher (gmanetto@unict.it), Dipartimento di Ingegneria Agraria, University of Catania, Italy.

Research developed within the 2005 MIUR project Machinery and their adjustment for a sustainable pest control in glasshouses.

The Authors contributed equally to the present study. crop, spraying equipment, droplet diameters from spray guns, operator movement, environmental conditions.

With respect to impact on the environment, pesticides are one of the most hazardous groups of contaminants fauna and environment in general [Van der Werf 1996] and contaminations can be both diffused (due to mixture applications) and localised (due to the preparation of spray-mixture and the cleaning of the machinery [Balsari 2008]).

The aim of the present study is the evaluation of foliar deposition, ground losses, and dermal operator exposure under field conditions in two tomato greenhouses. The experimental activity lasted two years. In the course of the first year, whose results are reported in this paper, we compared the operator walking directions (forward vs. backwards) in two different vegetative stages (pre-production vs. full development). In the second year, whose results will be reported in a later paper, we compared two models of spray lance and the effects of using two working pressures.

\section{Materials and methods}

\subsection{The crop}

The experimental trials were conducted in a farm at Ragusa, where pesticide application in greenhouses is usually performed by means of hand-held highpressure spray lances or spray guns, spraying volume rates ranging between 900 and $1800 \mathrm{~L} / \mathrm{ha}$ according to the stage of plant development. The task is normally accomplished by two operators: the first, inside the greenhouse, applies the mixture to the plants, while the second unwinds and rewinds the feeding hosepipe. Tank and pump are outside the greenhouse or in suitable service aisles.

Spraying trials were carried out in two greenhouses: the former with plants in pre-production stage, the latter with plants in full development stage. The chosen cultivar was Ikram, transplanted in twin-rows with a (full development) inter-row distance of $0.55 \mathrm{~m}$, an inter-twin-row distance of $1.25 \mathrm{~m}$, and row 
spacing of $0.35 \mathrm{~m}$. The corresponding values in preproduction were $0.50 \mathrm{~m}, 1.45 \mathrm{~m}$, and $0.35 \mathrm{~m}$. The resulting plant density was 31700 plants/ha in full development and 29300 plants/ha in pre-production.

The main geometric and morphological quantities of the plants were measured before the spraying trials: minimum and maximum height of the foliage to be sprayed, its thickness at several heights, Leaf Area Index $(L A I)$ and theoretical number of foliar layers $(n L)$. $n L$ is an estimate of the number of overlaid leaves, so its value, beside the $L A I$, affects the drop diffusion inside the canopy.

Geometrical measurements were made on 12 plants exhibiting average features, belonging to both rows of 6 different twin-rows. The $L A I$ was assessed by estimating the foliar surface of 4 (full development) or 8 (pre-production) plants. The foliar surface was estimated by computing the regression equation of the surface on the mass, based upon a sample of leaves representative of the whole plants [Cerruto, 2007]. The theoretical number of foliar layers was computed as a function of the $L A I$, according to the equation:

$$
n L=\frac{a \times L A I}{\Delta h}
$$

where $a$ is the average between-rows distance and $\Delta h$ the foliage height.

\subsection{The experimental design}

The experimental tests were carried out by means of the equipment used in the farm for spray application, i.e. a hand-held spray lance Yamaho C-6 (Figure 1) with two steel nozzles, each with two orifices. The size of the droplets was measured at the DEIAFA (University of Turin) according to the ISO 5682-1 regulation and is reported in Table 1.

The tank, the motor pump, and the 90 m hose-pipe, wound round a winding drum, were placed on a small trailer. All spraying tests were carried out at the pressure of 20 bar (measured at the pump output) that is

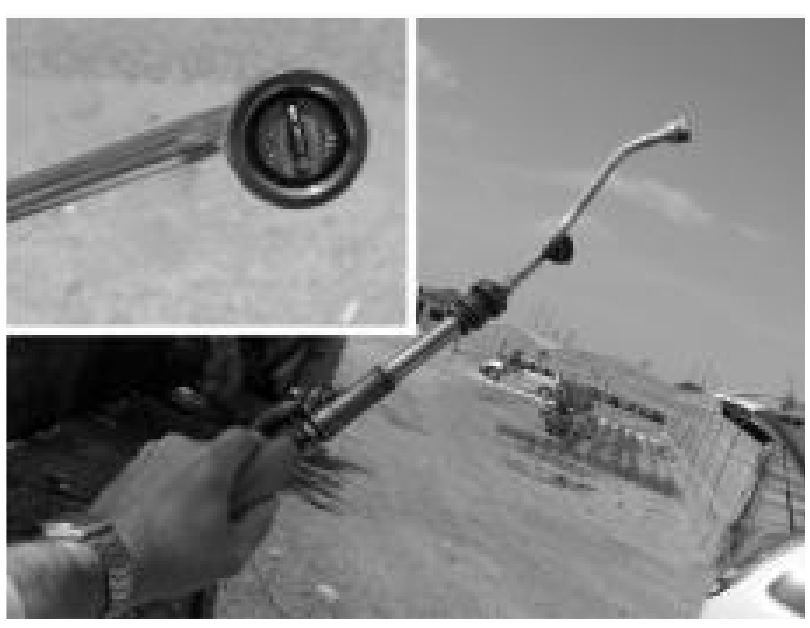

Fig. 1 - The Yamaho $C-6$ spray lance.

\begin{tabular}{llccc}
\hline $\begin{array}{l}\text { Pressure, } \\
\text { bar }\end{array}$ & $\begin{array}{l}\mathrm{D}_{30 \mathrm{~s}} \\
\mu \mathrm{m}\end{array}$ & $\begin{array}{c}\text { VMD, } \\
\mu \mathrm{m}\end{array}$ & $\begin{array}{c}\mathrm{D}_{\text {sos }} \\
\mu \mathrm{m}\end{array}$ & VMDNMD \\
\hline 5 & 177 & 349 & 580 & 3.9 \\
10 & 148 & 267 & 409 & 2.4 \\
15 & 130 & 230 & 271 & 2.3 \\
\hline
\end{tabular}

TABle 1 - Pulverisation properties of the Yamaho C-6 spray lance.

usually adopted in the farm for pesticide applications. The corresponding flow rate at the nozzles was $5.1 \mathrm{~L} / \mathrm{min}$.

According to the aims of the research, the spray lance was used in two different ways: the first with the operator walking forward, as is usual on the farm, and the second with the operator walking backwards. To cope with the practical difficulties, the experimental trials were arranged so that firstly we measured foliar deposition and ground losses, and then the operator dermal exposure.

During each trial the spraying time was measured, and the walking speed was calculated. Taking into account walking speed, flow rate at the nozzles at 20 bar, and crop layout, the experimental design was as reported in Table 2. The little difference between forward and backwards speed in each stage is due to the unfamiliarity of the operator with spraying while walking backwards, whereas the much higher difference between the two stages is due to the different plant features which required different volume application rates.

\begin{tabular}{|c|c|c|c|}
\hline Trials & Treatment & $\begin{array}{l}\text { Speed, } \\
\mathrm{km} / \mathrm{h}\end{array}$ & $\begin{array}{r}\text { Volume rate, } \\
\text { L/ha }\end{array}$ \\
\hline \multicolumn{4}{|c|}{ Full development } \\
\hline $\begin{array}{l}\text { Foliar deposition } \\
\text { and ground losses }\end{array}$ & Forward & 1.8 & 1798 \\
\hline $\begin{array}{l}\text { Foliar deposition } \\
\text { and ground losses }\end{array}$ & Backwards & 1.7 & 1915 \\
\hline Operator exposure & Forward & 2.2 & 1423 \\
\hline Operator exposire & Backwards & 1.9 & 1649 \\
\hline \multicolumn{4}{|c|}{ Pre-production } \\
\hline $\begin{array}{l}\text { Foliar deposition } \\
\text { and ground losses }\end{array}$ & Forward & 4.5 & 349 \\
\hline $\begin{array}{l}\text { Foliar deposition } \\
\text { and ground losses }\end{array}$ & Backwards & 3,4 & 984 \\
\hline Operator exposure & Forward & 3,9 & 865 \\
\hline Operator exposure & Backwards & 2.8 & 1185 \\
\hline
\end{tabular}

TABLE 2 - Experimental design.

\subsection{Foliar deposition measurement}

Experimental tests were performed spraying a water solution with $2 \%$ of food dye red Poinceau as a tracer and $0.05 \%$ of a surfactant. For each treatment three replicates were carried out, arranged according to a randomised block design. Each block consisted of a twin-row $30 \mathrm{~m}$ long. Blocks were divided into two equal parts and each area was sprayed on both rows according to the experimental design, walking in the 


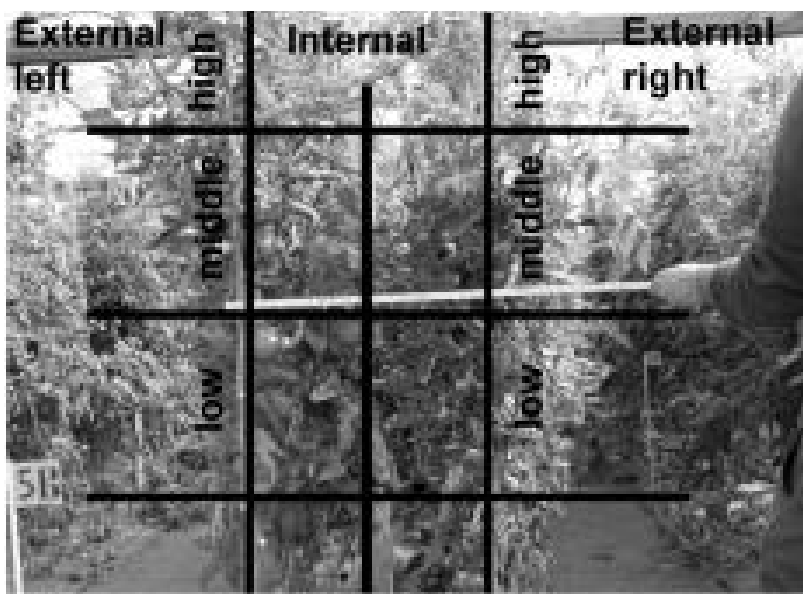

Fig. 2 - Sampling zones on the canopy.

space between twin-rows as an operator would do under normal conditions when spraying pesticides. Some twin-rows were kept unsprayed between the blocks, so to avoid the overlapping of deposits during replicates. During the applications, air temperature and relative humidity were measured.

Leaf sampling was carried out on both rows of the twin-rows, leaving out the borders so to limit the neighbourhood effects. Based upon the geometrical measurements, the canopy was divided up into three equal height zones (low, middle, and high) and into two depth zones (external and internal), as depicted in Figure 2.

After mixture application, 4 leaves were randomly picked on each of these 12 sampling zones ( 3 heights $\times 2$ depths $\times 2$ rows), totalling 48 leaves/replicate and then 144 leaves/treatment. Each leaf was placed in a suitably labelled plastic bag and then carried into the laboratory to measure the deposit. The measurement was carried out by means of a spectrophotometric technique. To allow comparison between trials, all foliar deposits $d$ were normalised to a reference volume rate $V_{N}$ according to:

$$
d_{n}=\frac{d}{V} V_{N}
$$

where $V$ is the applied volume rate. The reference volume rates were $1800 \mathrm{~L} / \mathrm{ha}$ at full foliage development and $900 \mathrm{~L} / \mathrm{ha}$ in pre-production stage. These two values were selected to reflect the different foliage development of the plants in the two experimental tests.

\subsection{Ground losses}

Ground losses were measured by means of collectors consisting of sheets of absorbent paper with a surface of $1053 \mathrm{~cm}^{2}(46.2 \times 22.8 \mathrm{~cm})$, spread over frames $10 \mathrm{~cm}$ high so to avoid contacts with the ground (Figure 3 ).

Ten frames were used for each replicate, arranged in two rows, $3 \mathrm{~m}$ spaced, across the sprayed twinrows. The 5 frames in each row, numbered from 1 to 5 from the left to the right, were disposed as depicted in Figure 3.

After spraying, the sheets were detached from the frames and put in suitably labelled plastic bags. The deposit was measured in the same way as the deposit on leaves had been measured. The values for each replicate were expressed as a percentage of the volume application rates. They were calculated by weigthing the deposits in each position, being the weights the widths of the sampling area: $0.625 \mathrm{~m}$ or $0.725 \mathrm{~m}$ for the positions $1,2,4$ and 5 , and $0.55 \mathrm{~m}$ or $0.50 \mathrm{~m}$ for the position 3 , at full development or preproduction stage respectively.

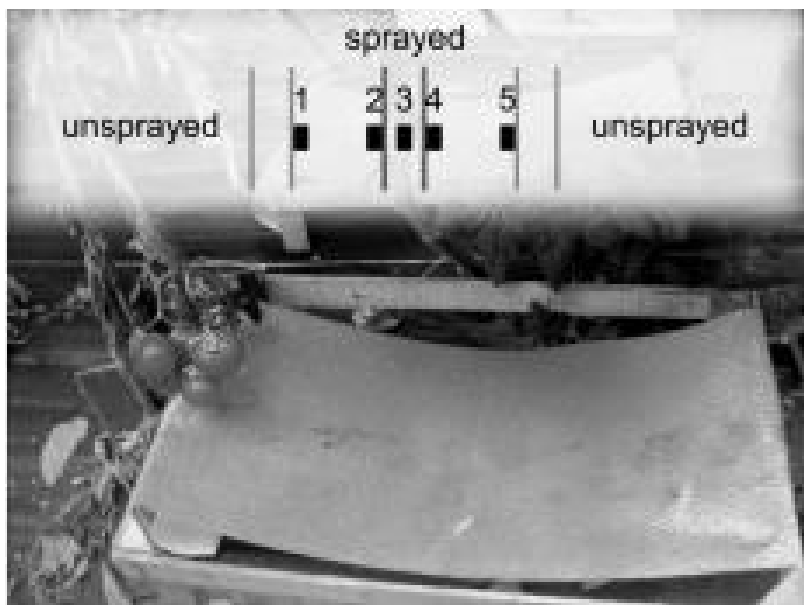

Fig. 3 - Frames to measure the ground losses.

\subsection{Operator exposure}

Experimental trials were arranged with a $60 \mathrm{~m}$ path (outward and return) between two twin-rows. Three replicates for each walking direction were carried out. During each replicate the operator was wearing a polypropylene disposable overall (Green Bay), completed with cover-shoes, respirator, and latex gloves.

After each replicate, the overall was cut in several pieces as depicted in Figure 4, and the exposure of each piece was again measured by means of the spectrophotometric technique. It was expressed in micro litres per square centimetre per working hour and in millilitres per working hour.

To account for the differences in the volume application rates, the values were again normalised to 1800 (full development stage) and 900 L/ha (pre-production stage).

\subsection{Data analysis}

The normalised foliar deposition data were analysed by means of the analysis of variance (ANOVA), performed separately for each stage. The analysis was carried out according to a split-plot design, assuming the operator walking direction as main plot factor and the sampling locations on the canopy as sub-plot factors. 


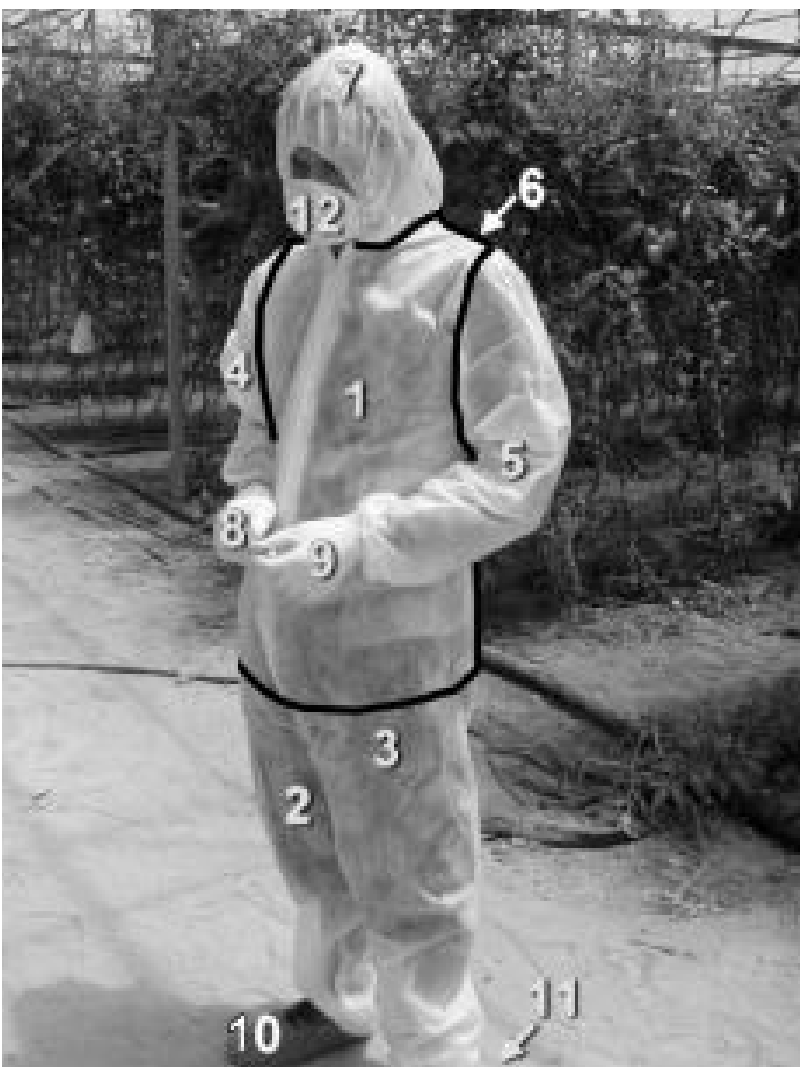

Fig. 4 - Overall to measure the operator dermal exposure.

The ANOVA was also applied to the ground losses data, expressed as percentage of volume application rates, and to the whole operator exposure data, expressed in millilitres per working hour, in order to compare both walking directions.

All computations and graphical representations were performed by means of the open source software R [R Development Core Team, 2007].

\section{Results and discussion}

\subsection{Plants features}

Table 3 reports the main geometrical quantities of the plants.

In the light of these measurements, the sampling zones were chosen as follows:

- full development trials, $0.5 \mathrm{~m}$ wide:

- low: from minimum up to $1.0 \mathrm{~m}$;

- middle: from $1.0 \mathrm{~m}$ up to $1.5 \mathrm{~m}$;

- high: from $1.5 \mathrm{~m}$ up to maximum;

- pre-production trials, $0.35 \mathrm{~m}$ wide:

- low: from minimum up to $0.55 \mathrm{~m}$;

- middle: from $0.55 \mathrm{~m}$ up to $0.90 \mathrm{~m}$;

- high: from $0.90 \mathrm{~m}$ up to maximum.

To measure $L A I$ and number of foliar layers, the regression analysis of surface $S\left[\mathrm{~cm}^{2}\right]$ on mass $m$ [g] produced the following equations:

$S=18.255 \cdot m+55.612$ full development

$S=21.584 \cdot m+41.154$ pre-production

\begin{tabular}{lcrr}
\hline Features & $\begin{array}{r}\text { mean, } \\
\mathrm{m}\end{array}$ & $\begin{array}{r}\text { std dev, } \\
\mathrm{m}\end{array}$ & $\begin{array}{r}\mathrm{CV} \\
\%\end{array}$ \\
\hline & Full development & & \\
\hline Minimum height & 0.49 & 0.13 & 27 \\
Maximum beight & 1.98 & 0.05 & 3 \\
Width at $0.6 \mathrm{~m}$ & 0.46 & 0.12 & 27 \\
Width at $1.0 \mathrm{~m}$ & 0.48 & 0.07 & 15 \\
Width at $1.4 \mathrm{~m}$ & 0.45 & 0.09 & 19 \\
Width at $1.8 \mathrm{~m}$ & 0.36 & 0.12 & 34 \\
\hline & Pre-production & & \\
\hline Minimum height & 0.19 & 0.05 & 26 \\
Maximum height & 1.23 & 0.10 & 8 \\
Width at $0.4 \mathrm{~m}$ & 0.70 & 0.15 & 21 \\
Width at $0.8 \mathrm{~m}$ & 0.61 & 0.12 & 20 \\
Width an $1.2 \mathrm{~m}$ & 0.28 & 0.11 & 37 \\
\hline
\end{tabular}

TABLE 3 - Main features of the foliage to be sprayed.

\begin{tabular}{lllll}
\hline Features & High & Middle & Low & Total \\
\hline \multicolumn{5}{c}{ Full development } \\
\hline$L A l, \mathrm{~m}^{2} / \mathrm{m}^{2}$ & 1.89 & 2.25 & 1.66 & 5.80 \\
$n L$ & 3.41 & 4.04 & 2.98 & 3.48 \\
\hline \multicolumn{5}{c}{ Pre-production } \\
\hline$L A l, \mathrm{~m}^{2} / \mathrm{m}^{2}$ & 0.31 & 0.90 & 0.88 & 2.09 \\
$n L$ & 0.86 & 2.50 & 2.46 & 1.94 \\
\hline
\end{tabular}

TABLE $4-L A I$ and number of foliar layers of the plants.

The determination coefficients were 0.931 and 0.971 respectively, both highly significant.

Based on these equations, the morphological quantities of the plants were calculated as follows in Table 4.

\subsection{Full development trials}

\subsubsection{Foliar deposition}

The full development trials were carried out on April 26, 2006, between 9:50 and 10:46. The average temperature inside the greenhouse was $18{ }^{\circ} \mathrm{C}$, the relative humidity $72 \%$.

The analysis of variance of the foliar deposits normalised at $1800 \mathrm{~L} /$ ha showed no statistical significant differences between the two walking directions (Figure 5): $1.43 \mu \mathrm{L} / \mathrm{cm}^{2}$ walking forward and 1.73 $\mu \mathrm{L} / \mathrm{cm}^{2}$ walking backwards.

This overall result was however affected by the sampling depth $(\mathrm{p}=0.029)$ : in fact, whereas the average deposition on the external leaves was 2.6 times greater than that on the internal leaves (2.27 vs. 0.88 $\mu \mathrm{L} / \mathrm{cm}^{2}$, Figure 5), splitting the data with respect to the walking direction, the results reported in Figure 6 were obtained.

It shows that both walking directions produced the same foliar deposits on the internal leaves, whereas walking backwards produced a significantly higher deposition on the external leaves (2.58 vs. 1.97 $\mu \mathrm{L} / \mathrm{cm}^{2}$ ).

Further significant differences were observed among the three sampling heights (Figure 5). The 


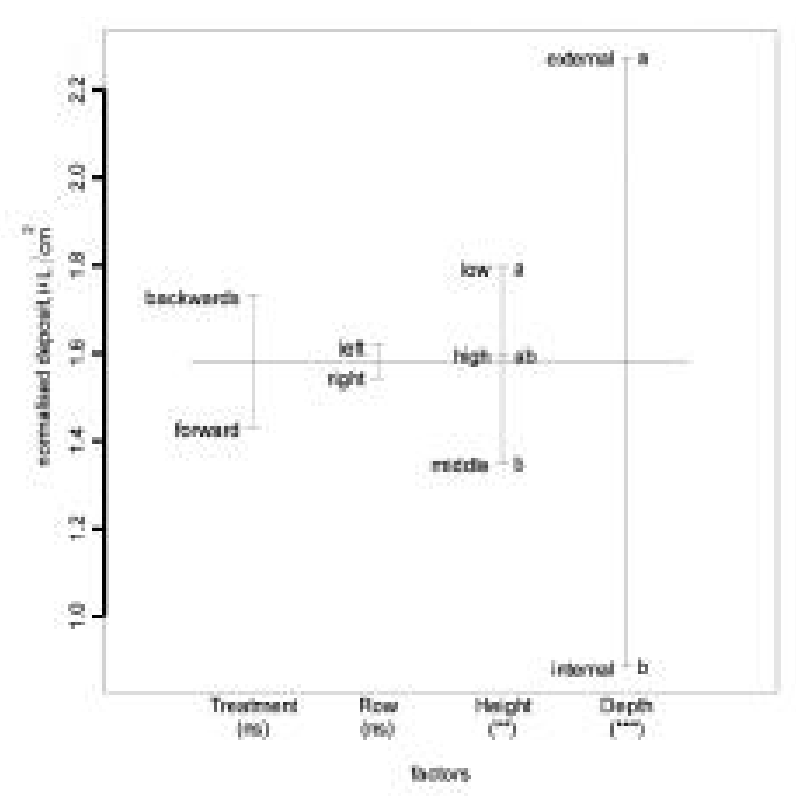

Fig. 5 - Plot design of the full development trials (mean separation by HSD Tukey test at $5 \%$ level).

lowest deposition was observed in the middle zone, because of the highest value of $L A I$ and number of foliar layers (Table 4).

Finally, no significant differences were observed between the two rows of the twin-rows (Figure 5): the normalised deposit was $1.62 \mu \mathrm{L} / \mathrm{cm}^{2}$ on the left row and $1.54 \mu \mathrm{L} / \mathrm{cm}^{2}$ on the right one.

The overall uniformity, expressed as a coefficient of variation (CV, Table 5), was higher on the external leaves walking backwards (39\% vs. $49 \%)$ and substantially the same on the internal leaves walking in both directions (63\% vs. $64 \%)$.

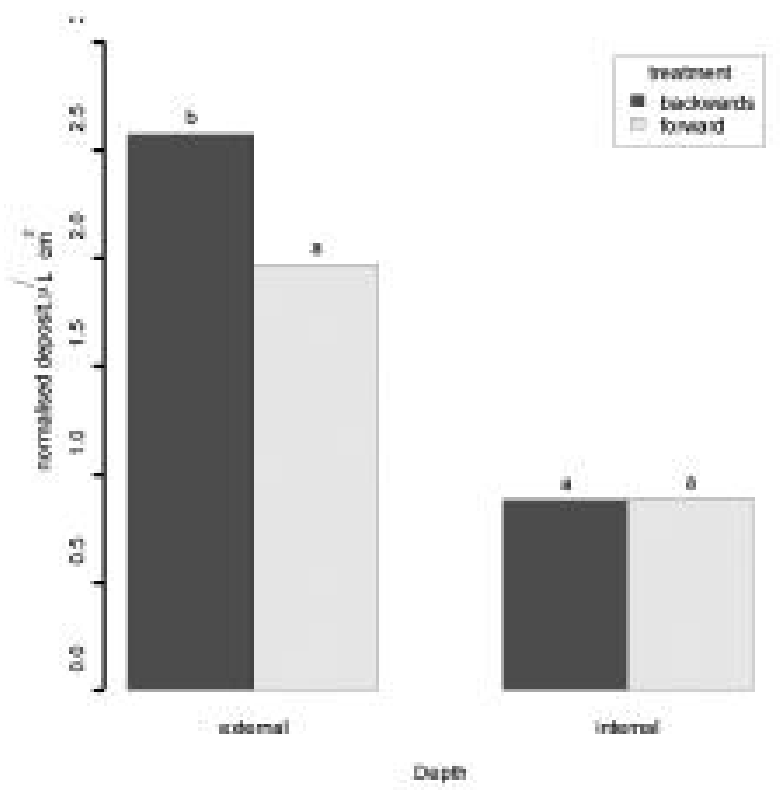

Fig. 6 - Normalised deposit on the two depth layers (mean separation at each depth by HSD Tukey test at 5\% level).

\begin{tabular}{lclll}
\hline Height & Low & Middle & High & Total \\
\hline Depth & \multicolumn{5}{c}{ Forward } \\
\hline Extemal & 46 & 50 & 46 & 49 \\
Internal & 91 & 64 & 40 & 64 \\
Total & 77 & 63 & 57 & 67 \\
\hline Depth & \multicolumn{5}{c}{ Backwards } \\
\hline External & 37 & 35 & 44 & 39 \\
Internal & 47 & 80 & 47 & 63 \\
Total & 58 & 77 & 70 & 68 \\
\hline
\end{tabular}

TABLE 5 - Coefficient of variation $(\mathrm{CV}, \%)$ of the foliar deposits in the full development trials.

\subsubsection{Ground losses}

Normalised deposits were not affected by treatments, but only by sampling positions (Table 6). It emerged that under the sprayed twin-row (positions 2, 3 , and 4 , Figure 3 ) the normalised deposits were significantly higher $(\mathrm{p}<1 \%)$ than in positions 1 and 5 (3.39 vs. $0.48 \mu \mathrm{L} / \mathrm{cm}^{2}$ on average). Moreover, while in positions 1 and 5 the normalised deposits were almost the same with both treatments, in positions 2, 3, and 4 they were higher $(\mathrm{p}=0.06)$ walking backwards (3.98 vs. $2.81 \mu \mathrm{L} / \mathrm{cm}^{2}$ ).

The fraction of the applied volume rate on the ground was not statistically affected by the treatment. It was on average $16.8 \%$ ( $302 \mathrm{~L} / \mathrm{ha}$ ) walking forward and $23.5 \%$ (424 L/ha) walking backwards.

\begin{tabular}{lcccccc}
\hline Positions & 1 & 2 & 3 & 4 & \multicolumn{1}{c}{5} & Total \\
\hline Forward & 0.47 & 2.99 & 3.04 & 2.39 & 0.19 & $1.82^{15}$ \\
Backwards & 0.50 & 4.07 & 3.79 & 4.07 & 0.22 & $2.53^{n}$ \\
Total & $0.49^{\mathrm{b}}$ & $3.53^{\mathrm{*}}$ & $3.42^{\mathrm{N}}$ & $3.23^{\mathrm{*}}$ & $0.21^{\mathrm{b}}$ & 2.17 \\
\hline
\end{tabular}

TABLE 6 - Ground losses $\left(\mu \mathrm{L} / \mathrm{cm}^{2}\right)$ in full development trials (mean separation among positions by HSD Tukey test at $5 \%$ level).

\subsubsection{Operator exposure}

Table 7 reports the operator exposure values, expressed as normalised deposits in micro litres per square centimetre per working hour and as millilitres of mixture which came into contact with each piece of overall per working hour. On average, the dermal exposure walking forward was more than 8 times that of

\begin{tabular}{|c|c|c|c|c|c|}
\hline \multirow[b]{2}{*}{ Zone } & \multicolumn{2}{|c|}{$\mathrm{A}\left(\mathrm{f} / \mathrm{cm}^{2} \mathrm{~h}\right)$} & \multicolumn{2}{|c|}{$\mathrm{mLh}$} & \multirow[b]{2}{*}{ Ratio } \\
\hline & Forward & Badkuards & Forwand & Boxkwands & \\
\hline Head & 3.62 & 0.32 & 6.5 & 0.6 & 11.4 \\
\hline Respirator & 2.14 & 1.10 & 0.3 & 02 & 20 \\
\hline Chest & 6.64 & 0.55 & 43.8 & 3.6 & 120 \\
\hline Back & 3.69 & 0.56 & 24.3 & 3.9 & 63 \\
\hline Right arn & 2536 & 0.45 & 685 & 1.0 & 70.7 \\
\hline Left arm & 6.33 & 1.14 & 17.1 & 3.1 & 56 \\
\hline Rigle hand & 39.88 & 2.12 & 20.4 & 1.1 & 18.8 \\
\hline 1.eft hand & 20.82 & 2.45 & 10.7 & 13 & 8.5 \\
\hline Right leg & 18.19 & $1.5 \%$ & 87.1 & 72 & 12.1 \\
\hline Left leg & 15.40 & 3.21 & 73.8 & 15.4 & 4.8 \\
\hline Righx tsot & 27.85 & 4.58 & 28.5 & 4.7 & 6.1 \\
\hline 1.eft foot & 20.16 & 4.86 & 20.6 & 50 & 4.1 \\
\hline Toal & 190,48 & 22.75 & 401.6 & 46.9 & 8.0 \\
\hline
\end{tabular}

TABLE 7 - Operator exposure in full development trials. 
walking backwards: $402 \mathrm{~mL} / \mathrm{h}$ vs. $47 \mathrm{~mL} / \mathrm{h}$ (Kruskal test significant at $\mathrm{p}=0.0495$ with only three replicates). The ratio was greater than 10 for several body parts, namely the right arm, right hand, right leg, and chest.

This big difference is mainly due to the fact that, when the operator walked forward, his or her body partially came into contact with the cloud of spray, whereas when he or she walked backwards, there was time for the cloud of spray to deposit itself on the ground and/or on the crop.

Looking at the results in more depth, we may observe that, walking forward, the right side of the operator was always more exposed than the left side, whereas the opposite occurred when walking backwards. This was because the operator brushed his or her body against the sprayed plants: when he or she walked forward, he or she brushed the right side against a sprayed row during both the outward and return path, and the left side only brushed against the sprayed row in the course of the return path. When he or she walked backwards, only during the return path and only his or her left side brushed against a sprayed row.

Legs were the body part that accounted for the greatest exposure: $40 \%$ walking forward and $48 \%$ walking backwards. This is because the foliage to be sprayed barely rose above ground level (Table 3), so the operator, oscillating the spray lance, was inevitably directing the spray jet against his or her lower limbs. In addition, walking forward, upper limbs (arms and hands) accounted for 29\%, lower limbs (legs and feet) for 52\%, trunk (chest and back) for $17 \%$, and head and respirator for $2 \%$ of the overall exposure. The corresponding values walking backwards were $14 \%, 69 \%, 16 \%$, and $1 \%$.

\subsection{Pre-production trials}

\subsubsection{Foliar deposition}

The trials were carried out on July 11, 2006, between 18:51 and 19:21. The average temperature inside the greenhouse was $26^{\circ} \mathrm{C}$, the average relative humidity $64 \%$.

The analysis of variance confirmed some of the previous results (Figure 7), particularly those on the effects of the treatment. In fact, the average foliar deposition was unaffected by the walking direction: $1.16 \mu \mathrm{L} / \mathrm{cm}^{2}$ walking backwards and $1.53 \mu \mathrm{L} / \mathrm{cm}^{2}$ walking forward. It should be noted that these foliar deposits are comparable to those obtained in the previous experiments, even if the reference volume application rate is halved ( 900 vs. $1800 \mathrm{~L} / \mathrm{ha})$. As in the pre-production stage the plant height was about half that in full development stage, to obtain constant foliar deposition one would recommend that volume rates were proportional to the plant height, confirming the results obtained by Pergher [2007] and Franchi [2006] in vineyard.

On the whole, foliar deposits showed differences

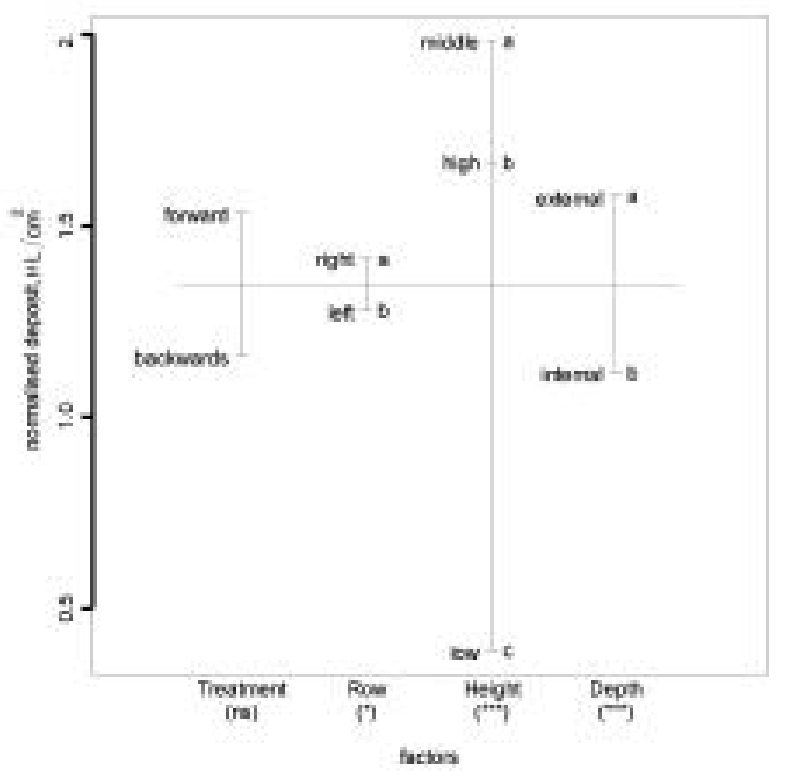

Fig. 7 - Plot design of the pre-production trials (mean separation by HSD Tukey test at $5 \%$ level).

among the sampling locations greater than those observed in full development trials. This could be due to the different spraying techniques. In fact, whereas in full development trials the operator was oscillating the spray lance from top to bottom and vice versa, directing the spray jet on all the foliar wall, in these trials the operator was holding the spray lance, directing the spray jet only from top to bottom. This produced a very low deposition on the low zone $\left(0.39 \mu \mathrm{L} / \mathrm{cm}^{2}\right)$, compared to that on the middle $\left(1.98 \mu \mathrm{L} / \mathrm{cm}^{2}\right)$ and the high $\left(1.67 \mu \mathrm{L} / \mathrm{cm}^{2}\right)$ zone. As a consequence, the differences between middle and low zones were higher than those between the external and internal layer (1.58 vs. $\left.1.12 \mu \mathrm{L} / \mathrm{cm}^{2}\right)$.

Moreover, the differences among the three height zones were affected by treatment and sampling depth (Table 8). To be precise, while on low and middle zones the foliar deposit was the same on both layers (external and internal), on high zones it was significantly higher on the external layer (2.25 vs. 1.08 $\left.\mu \mathrm{L} / \mathrm{cm}^{2}\right)$. This is due to the spraying technique: in fact, parts of the spray jet, directed from top to bottom, crossed the row the operator was spraying and reached the middle and low band of the internal layer of the other row of the same twin-row, leaving a lower deposit on the internal high zone.

The foliar deposits at each height zone were also affected by the treatment factor (Table 8). In fact,

\begin{tabular}{llccc}
\hline Factors & Value & Low & Middle & High \\
\hline Treatment & Forward & $0.39^{\mathrm{a}}$ & $2.42^{\mathrm{a}}$ & $1.79^{\mathrm{a}}$ \\
& Backwards & $0.39^{\mathrm{a}}$ & $1.55^{\mathrm{b}}$ & $1.54^{\mathrm{a}}$ \\
\multirow{3}{*}{ Depth } & Exwernal & $0.41^{\mathrm{a}}$ & $2.08^{\mathrm{a}}$ & $2.29^{\mathrm{a}}$ \\
& Intemal & $0.37^{\mathrm{a}}$ & $1.89^{\mathrm{a}}$ & $1.08^{\mathrm{h}}$ \\
\hline
\end{tabular}

TABLE 8 - Foliar deposits $\left(\mu \mathrm{L} / \mathrm{cm}^{2}\right)$ in pre-production trials (mean separation at each height by HSD Tukey test at 5\% level). 


\begin{tabular}{lcccc}
\hline Height & Low & Middle & High & Total \\
\hline Depth & \multicolumn{5}{c}{ Fonward } \\
\hline External & 79 & 24 & 47 & 70 \\
Internal & 62 & 32 & 40 & 77 \\
Total & 70 & 29 & 62 & 75 \\
\hline Depuh & \multicolumn{5}{c}{ Backwards } \\
\hline External & 66 & 42 & 33 & 65 \\
Internal & 52 & 27 & 31 & 55 \\
Total & 61 & 41 & 46 & 68 \\
\hline
\end{tabular}

TABLE 9 - Coefficient of variation $(\mathrm{CV}, \%)$ of the foliar deposits in the pre-production trials.

while in low and high zones the foliar deposit was the same in both walking directions, in the middle zone it was significantly higher when walking forward.

Finally, the coefficients of variation of foliar deposits (Table 9) were lower when walking backwards in almost all sampling locations.

\subsubsection{Ground losses}

The pre-production trials confirmed the results of the previous trials, i.e. no statistical significant differences between the treatments and significant differences among the sampling positions (Table 10). On average, the normalised deposits were $0.91 \mu \mathrm{L} / \mathrm{cm}^{2}$ walking forwards and $0.75 \mu \mathrm{L} / \mathrm{cm}^{2}$ walking backwards, $0.43 \mu \mathrm{L} / \mathrm{cm}^{2}$ in positions 1 and 5 and 1.10 $\mu \mathrm{L} / \mathrm{cm}^{2}$ in positions 2,3 , and 4 .

\begin{tabular}{lcccccc}
\hline Positions & 1 & 2 & 3 & 4 & 5 & \multicolumn{1}{c}{ Total } \\
\hline Forward & 0.47 & 1.29 & 1.46 & 0.94 & 0.41 & $0.91^{15}$ \\
Backwards & 0.36 & 0.82 & 0.90 & 1.19 & 0.48 & $0.75^{\mathrm{s}}$ \\
Total & $0.41^{\mathrm{*}}$ & $1.05^{\mathrm{a}}$ & $1.18^{\mathrm{a}}$ & $1.06^{\mathrm{a}}$ & $0.44^{\mathrm{b}}$ & 0.83 \\
\hline
\end{tabular}

TABLE $10-$ Ground losses $\left(\mu \mathrm{L} / \mathrm{cm}^{2}\right)$ in pre-production trials (mean separation among positions by Kruskal test at 5\% level).

The fraction of the applied volume rate on the ground was again unaffected by the walking direction. It was $17.0 \%$ walking forward $(153 \mathrm{~L} /$ ha with a reference value of $900 \mathrm{~L} / \mathrm{ha}$ ) and $14.3 \%$ walking backwards (129 L/ha).

\subsubsection{Operator exposure}

The results reaffirmed those obtained in full development stage, even if the differences between the two treatments were lower: forward $=114 \mathrm{~mL} / \mathrm{h}$, backwards $=28 \mathrm{~mL} / \mathrm{h}$, ratio $=4.1($ Table 11$)$. This was due to the different plant features which required different volume application rates ( 900 vs. $1800 \mathrm{~L} / \mathrm{ha}$ ) and different spraying techniques (spray lance fixed vs. spray lance oscillating). As a consequence, the body parts more exposed were legs and feet, which together accounted for 84 percent (forward) and 79 percent (backwards) of the total exposure.

The greatest unitary deposits were found, with both walking directions, on feet (directly from the spray

\begin{tabular}{|c|c|c|c|c|c|}
\hline \multirow[b]{2}{*}{ Zone } & \multicolumn{2}{|c|}{$\mu L \cdot\left(\mathrm{cm}^{2} \cdot \mathrm{h}\right)$} & \multicolumn{2}{|c|}{ mLh } & \multirow[b]{2}{*}{ Puti: } \\
\hline & Formand & Backwards & Forwed & Buckwiedh & \\
\hline Hesd & .028 & 0.04 & 0.5 & 0.1 & 6.3 \\
\hline Pespirater & 0.72 & 0.48 & 0.1 & 0.1 & 1.5 \\
\hline Chest & 0.90 & 0.15 & 6.0 & 1.0 & 6.2 \\
\hline Back & 0.71 & 0.27 & 4.7 & 1.8 & 2 \\
\hline RGhit am & a.s6 & 0.22 & 23 & 0.6 & 3 \\
\hline Left anm & 9.73 & 0.17 & 2.0 & 0.5 & 4.2 \\
\hline Reght hand & 3.51 & 2.98 & 1.8 & 1.5 & 1.2 \\
\hline Left hand & 1.60 & 0.57 & $0 . \bar{\varepsilon}$ & 0.3 & 2.8 \\
\hline Reght log & 8.28 & 1.42 & 39.7 & 6.8 & 5.8 \\
\hline Lefl ks & 4.16 & 0.72 & 19.9 & 3.5 & 5.7 \\
\hline Right foos & $17.8 \mathrm{~T}$ & 6.47 & 18.3 & 6.6 & \\
\hline Left foos & 13.08 & 5.09 & 17.5 & 5.2 & 3.4 \\
\hline Tatal & 56.70 & 18.58 & 113.5 & 27.9 & 4.1 \\
\hline
\end{tabular}

TABLE 11 - Operator exposure in pre-production trials.

lance and from the ground), legs (the body parts nearest to the sprayed cloud), and right hand (which was holding the spray lance).

\section{Conclusions}

The experimental trials allow for the following conclusions:

- The average foliar deposition was not affected by walking direction. However, the uniformity of deposits on the canopy should be improved, especially in pre-production stage, when the low part of the canopy was much less sprayed than the middle and high part ( 0.39 vs. $1.82 \mu \mathrm{L} / \mathrm{cm}^{2}$ on average) due to the spraying technique with the spray jet directed from top to bottom. At full foliage development, the differences among the three height zones were much more reduced, again due the spraying technique which involved oscillating the spray lance. Some differences were also observed between the external and internal layer of the canopy, especially at full foliage development, when $L A I$ and the number of foliar layers were higher. These differences could probably be reduced by means of air assisted sprayers, which help the droplet transportation inside the canopy. Further research is necessary to assess this possibility.

- Despite the different volume application rates, average foliar deposits were comparable in the two trials. This points to the necessity of adjusting the doses per hectare by taking into account the height and foliar density of the plants.

- Due to the variations in walking speeds, big differences in volume application rates were observed among the replicates (up to $60 \%$ from minimum to maximum). This could affect the deposit uniformity on fruits, increasing the risks of exceeding the allowable limits. Further research exploiting mechanised solutions which ensure constant volume application rates and safeguarding operator safety is necessary [Balloni, 2008].

- Ground losses ranged between 14.3 percent up to 23.5 percent of the applied volume rates, without statistical significant differences between the two walking directions. 
- Operator exposure can be greatly reduced (up to 8 times at full foliage development, from $402 \mathrm{~mL} / \mathrm{h}$ to $47 \mathrm{~mL} / \mathrm{h}$ with a reference volume rate of 1800 L/ha) by walking backwards, without affecting the quality of application and working capacity.

\section{References}

Balloni S., Caruso L., Cerruto E., Emma G., Schillaci G., A Prototype of Self-Propelled Sprayer to Reduce Operator Exposure in Greenhouse Treatment, Proceedings on CDROM of the International Conference on "Innovation Technology to Empower Safety, Health and Welfare in Agriculture and Agro-food Systems", Ragusa, Italy, September 15-17, 2008.

Balsari P., Marucco P., Oggero G., Reduction of Water Contamination from Pesticides through the Application of the Best Management Practices defined by the TOPPS Project, Proceedings on CD-ROM of the International Conference on "Innovation Technology to Empower Safety, Health and Welfare in Agriculture and Agro-food Systems", Ragusa, Italy, September 15-17, 2008.

Bjugstad N., Torgrimsen T., Operator Safety and Plant Deposits when using Pesticides in Greenhouses, Journal of Agricultural Engineering Research, 1996, 65(3), 205-212.

Cerruto E., Balsari P., Oggero G., Friso D., Guarella A., Raffaelli M., Operator Safety during Pesticide Application in Greenhouses: a Survey on Italian Situation, GreenSys 2007, Naples, October 4-6, 2007, ISHS Acta Horticulturae 801, November 25, 2008, 2, 1507-1514.

Cerruto E., Further Studies on the Variation of Spray Deposits in Vineyards with Airflow Rate and Volume Rate, Journal of Agricultural Engineering - Rivista di Ingegneria Agraria, 2007, 1, 31-38.

Franchi A., Barani A., Giosué S., Prime osservazioni sull'impiego del modello di calibratura dello spray UCR e dei dosaggi in applicazioni su Vitis vinifera (Preliminary evaluations of UCR spray application method and dosage in treatments of vines against downy and powdery mildew), Proceedings Giornate Fitopatologiche 2006, 1, 513-520.

Garrido Frenich A., Aguilera P.A., Egea Gonzalez F., Castro Cano M.L., Martinez Galera M., Martinez Vidal J.L., Soler M., Dermal Exposure to Pesticides in Greenhouses Workers: Discrimination and Selection of Variables for the Design of Monitoring Programs, Environmental Monitoring and Assessment, 2002, 80, 51-63.

International Standard ISO 5682-1, Equipment for Crop Protection - Spraying Equipment. Part 1: Test Methods for Sprayer Nozzles, second edition, 1996.

Italian Central Statistics Institute, www.istat.it, 2008.

Nuyttens D., Windey S., Sonck B., Comparison of Operator Exposure for five different Greenhouse Spraying Applications, XXXI CIOSTA-CIGR V Congress "Increasing Work Efficiency in Agriculture, Horticulture and Forestry", September 19-21, 2005, University of Hohenheim, Stuttgart, Germany, 98-105.
Pergher G., Petris R., Canopy Structure and Deposition Efficiency of Vineyard Sprayers, Journal of Agricultural Engineering - Rivista di Ingegneria Agraria, 2007, 2, 31-38.

R Development Core Team, R: A Language and Environment for Statistical Computing, R Foundation for Statistical Computing, Vienna, Austria, ISBN 3-900051-07-0, 2007, URL http://www.R-project.org.

Tuomainen A., Kangas J.A., Meuling W.J.A., Glass R.C., Monitoring of Pesticide Applicators for Potential Dermal Exposure to Malathion and Biomarkers in Urine, Toxicology Letters, 2002, 134, 125-132.

Van der Werf H.M.G., Assessing the Impact of Pesticides on the Environment, Agricultural, Ecosystems and Environment, 1996, 60, 81-96.

\section{SUMMARY}

The present paper reports the results of some spray application trials carried out in two tomato greenhouses to assess foliar deposition, ground losses, and dermal operator exposure when using hand-held highpressure spray lances. Two operating ways (forward vs. backwards operator movement) and two different plant vegetative stages (pre-production vs. full development) were taken into consideration.

An experimental design with one factor (the operator walking direction) was adopted, arranged according to a randomised block design with three replicates. Volume application rates were settled according to the plant development: $900 \mathrm{~L} / \mathrm{ha}$ in pre-production stage and $1800 \mathrm{~L} /$ ha at full development stage.

The results showed no statistically significant differences in the mean foliar deposition between the two walking directions in both development stages. The greatest differences among the sampling locations were observed in pre-production stage, when, due to the spraying technique (spray jet directed from top to bottom), the foliar deposits in the low part of the canopy were much lower than those in the middle and high part.

Also ground losses were unaffected by walking direction: they ranged on average from $14.3 \%$ to $23.5 \%$ of the applied volume rate.

Finally, the dermal operator exposure was greatly affected by walking direction: at full development stage, it was 8 times higher walking forward than walking backwards. So, this simple change in field practice can noticeably improve the operator safety, without penalising working capacity and quality of deposition.

Keywords: Pesticide, Spray lance, Foliar deposition, Ground losses, Operator exposure. 